\title{
Particle Size Distribution of the Coal Bottom Ash from the Large Combustion Plant
}

\section{Olimpia Ghermec ${ }^{1, a^{*}}$, Ionela Bucse ${ }^{1, b}$ and Mariana Ciobanu ${ }^{1, c}$}

\author{
${ }^{1}$ University of Craiova, Faculty of Mechanics, Department of Engineering and Management of \\ Technological Systems, $1^{\text {st }}$ Calugareni street, 220037, Drobeta Turnu Severin, Romania \\ aolimpia_ghermec@yahoo.com, bbucse_ionela@yahoo.com, ${ }^{c}$ maryana_ciobanu@yahoo.com
}

Keywords: coal bottom ash, particle size distribution, particulate matter

\begin{abstract}
Human existence is dependent on the consumption of electricity and of thermal energy. One of the environmental problems is represented by the particulate matter with the diameter of less than $2.5 \mathrm{~mm}$ derived from combustion of coal. In order to find solutions to reduce emissions at source, the particle size distribution of the coal bottom ash after removing it from the steam boiler of the large combustion plant from Romag Halanga in Drobeta Turnu - Severin area was determined. Dry particle size distribution shows that the major fraction is one that has a particle size of $125 \mu \mathrm{m}$. Particle size distribution in the smallest size fraction was performed with laser diffraction particle size analyzer Brookhaven 90 Plus Nanoparticle Size Analyzer. Particle size distribution shows that in the composition of the coal bottom ash were found particles with nanometric dimensions.
\end{abstract}

\section{Introduction}

Human existence is dependent on the consumption of electricity and thermal energy. Alternatives fuels that can be used to produce energy in large combustion plants are not many: fossil fuels or nuclear fuel. Of these, burns of fossil fuels, including coal, oil and natural gas, are currently the world's primary energy source. International Energy Statistics shows that in UE-27 consumption of coal for energy production has evolved in recent years as shown in fig. 1 [1].

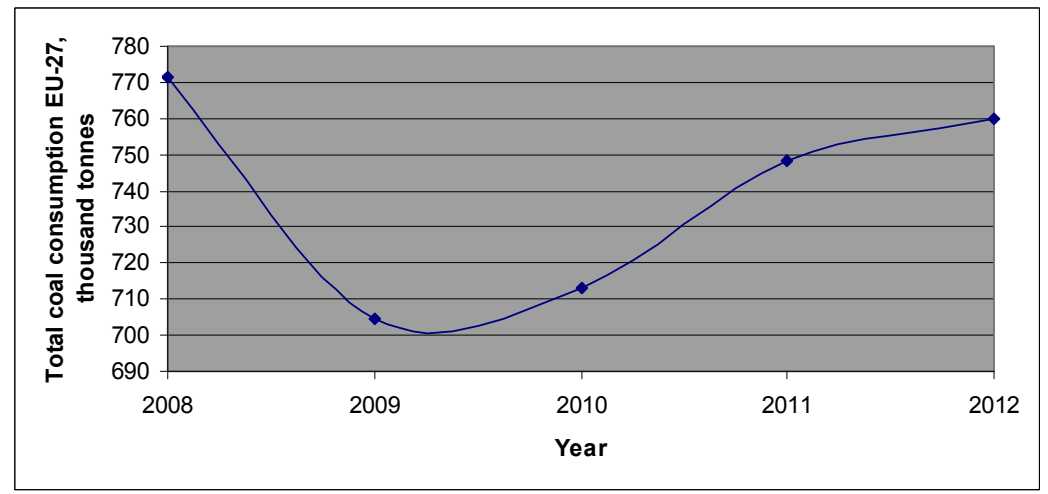

Fig.1 Total coal consumption for energy production in EU-27

Analyzing the above data, it can be seen that after a decline in coal consumption in 2009 , in the next few years the consumption has been increasing steadily, with the European economic recovery from the economic crisis. Coal will remain for the next few years an important source of energy although it is well known the impact of the large combustion plant on the environment.

During the combustion of coal, the organic matter is burned and the inorganic minerals change in the form of ash. Pulverized coal boilers produce a large amount of coal fly ash (80-90\% of total coal ash). Approximately $15-20 \%$ of total coal ash is bottom ash [2]. At the level of the European Union, there is a growing interest for the accumulation of information regarding coal fly ash, coal bottom ash and boiler slag. At the same time, it is remarked the importance of the research and the 
development in order to efficiently deal with the generated ash and with the purpose of finding possible applications of the combustion products of coal [3].

One of the environmental problems is the particulate matter with the diameter less than $2.5 \mathrm{~mm}$ derived from combustion of coal. These can remain suspended in the atmosphere for days or even weeks [4] and can move over hundreds of kilometers before they settle. Particulate matter with the diameter less than $2.5 \mathrm{~mm}$ is dangerous to human health because it causes asthma, sinusitis and chronic obstructive pulmonary disease or lung cancer. [5]

In this work are presented the results of the first research carried out on coal bottom ash taken from a steam boiler of the large combustion plant from Romag Prod Halanga, in Drobeta Turnu Severin area, whose capacity is of 420 tons of steam $/ \mathrm{h}$. In order to find solutions to reduce emissions at source of particulate matter with the diameter less than $2.5 \mathrm{~mm}$ it was determined the coal ash particle size distribution after removing it from the steam boiler.

\section{Materials and experimental procedure}

The material for the research has resulted as waste from the steam boiler which is supplied with coal milled with six ventilator grinding mills with hammers type MVC-4. The basic fuel recommended to be used is coal with the following characteristics:

- Inferior calorific power of $1850 \mathrm{kcal} / \mathrm{kg}$;

- Mass sulfur amount of $1.7 \%$ (according to lab analyses, medium value);

- Ash amount of $36.3 \%$ (according to lab analyses, medium value);

- Humidity of $42.9 \%$.

The samples of coal bottom ash were taken from several points situated at $30 \mathrm{~cm}$ depth from the ash dump of coal bottom ash [6]. There were taken 60 elementary samples that totals $68.45 \mathrm{~kg}$ coal bottom ash. They were combined through mixing in order to create an aggregate sample. Cone and quartering subsampling method was used in order to obtain an average representative sample.

This sample was first dried through heating in an oven at $150^{\circ} \mathrm{C}$ [7]. The first operation was the sieve analysis using a laboratory stacked six vibrating sieve. There were used metallic round sieves. The size of the sieves is shown in fig. 2 .

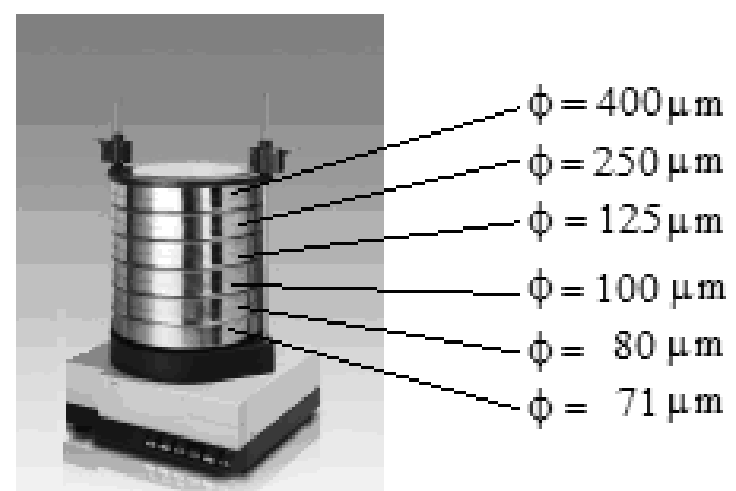

Fig.2 The laboratory stacked six vibrating sieve

There were weighed $1124.65 \mathrm{~g}$ of coal bottom ash before sieving. The material was sieved for 20 minutes. The quantity of ash from each sieve was weighed in order to be determined the particle size distribution of the ash, which is shown in figure 4.

The fraction with smaller dimensions than $71 \mu \mathrm{m}$ was analyzed in order to evaluate the content of particulate matter with a smaller diameter than $6 \mu \mathrm{m}$. Particle size distribution in the smallest size fraction was performed with laser diffraction (LD) particle size analyzer Brookhaven 90 Plus Nanoparticle Size Analyze as shown in fig. 3 [8]. The LD method involves the detection and analysis of the angular distribution of scattered light produced by a laser passing through a dilute dispersion of particles. 
For this, there were respected the prosivions of SR ISO 14887:2000, Sample Preparation Dispersing Procedures for Powders in Liquids: the test samples were dispersed in de - ionized water using Daxad ${ }^{\circledR} 23$ and ultrasonic disagglomeration. $0.100 \mathrm{~g}$ coal ash were dissolved in $50 \mathrm{ml}$ of de - ionized water and the solution was placed in ultrasonic disagglomeration for 5 minutes. In the cuvette of the apparaturs $2.5 \mathrm{ml}$ solution and $0.5 \mathrm{ml}$ daxad were out. The cuvette was placed in ultrasonic disagglomeration for 5 minutes and the put in the apparatus. Then the cuvette was put in the device. There were made 5 measurements of 1 minute each.

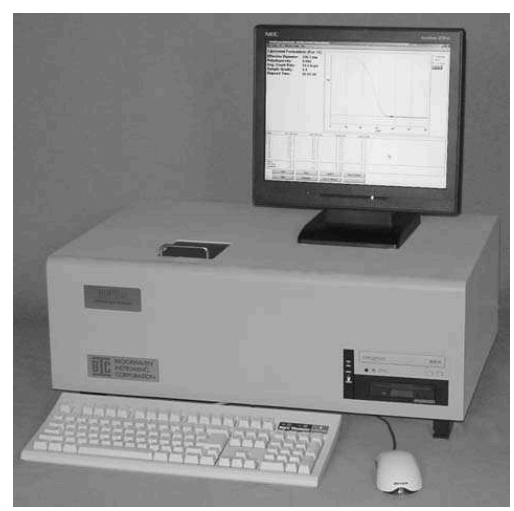

Fig.3 Brookhaven 90 Plus Nanoparticle Size Analyzer

\section{Results and discussions}

The particle size distribution was made by dry sieving. The obtained data are presented in fig. 4 from which it can be seen that the major fraction is the one that has a particle size of $125 \mu \mathrm{m}$ (65.7\% from the total coal ash weight) [9].

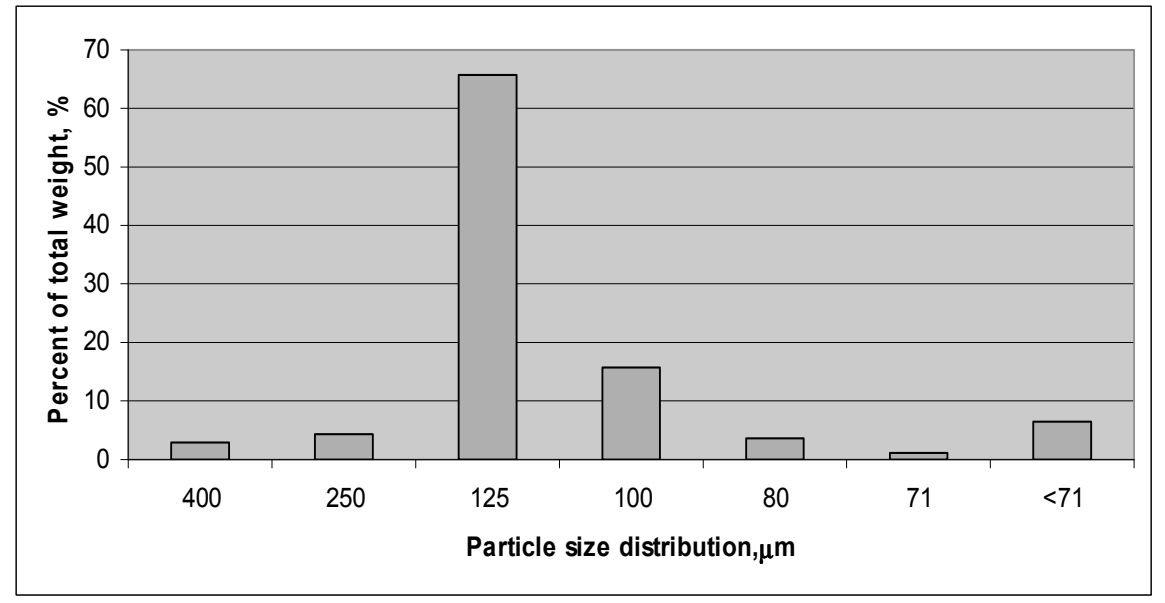

Fig.4 Dry particle size distribution

In specialty literature it is shown that coal bottom ash has a porous surface structure $[2,10]$. By diminishing the dimensions of the particles, it is increased the specific surface and this leads to a growth in their reactivity. This is why wet particle size distribution fraction less than $71 \mu \mathrm{m}(6.26 \%$ from the total coal bottom ash) has been studied. Brookhaven 90Plus Nanoparticle Size Analyzer was used to investigate particle size distribution in range from $2 \mathrm{~nm}$ to $6 \mu \mathrm{m}$. Results can be displayed on a volume, surface area, or number basis. The statistic interpretation of the distribution curve is made according to ISO 13320-1 Particle size analysis - Laser diffraction methods [11].

In fig. 5 is shown the particle size distribution of coal bottom ash in range from $2 \mathrm{~nm}$ to $6 \mu \mathrm{m}$ as a volume distribution as results of laser diffraction. On the particle size distribution there are three granulometric classes which are between the intervals of [187.4 - 293.9] nm, [722.5 - 1132.9] nm, 
respectively [3487.8 -3902.8$] \mathrm{nm}$. A common approach to define the distribution width is to cite three values on the x-axis, the D10, D50, and D90 as shown in fig. 6.

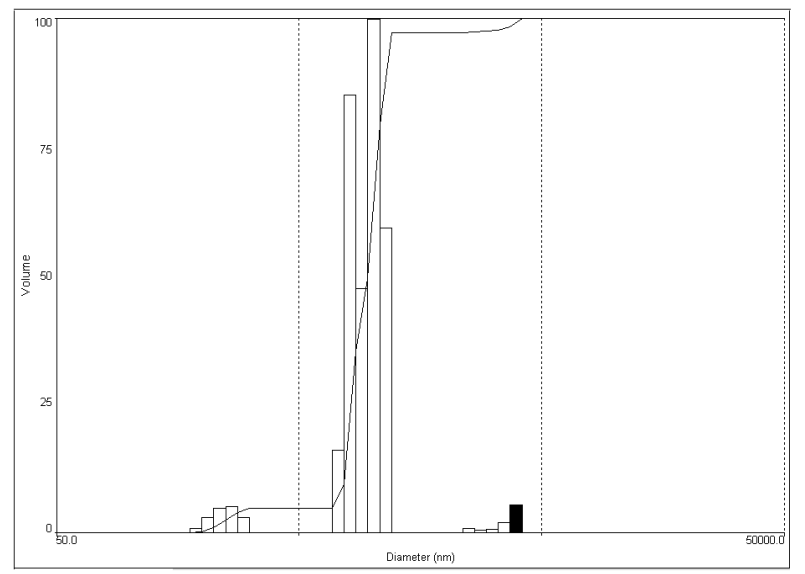

Fig.5 Particle size distribution of coal bottom ash in range from $2 \mathrm{~nm}$ to $6 \mu \mathrm{m}$ as a volume distribution
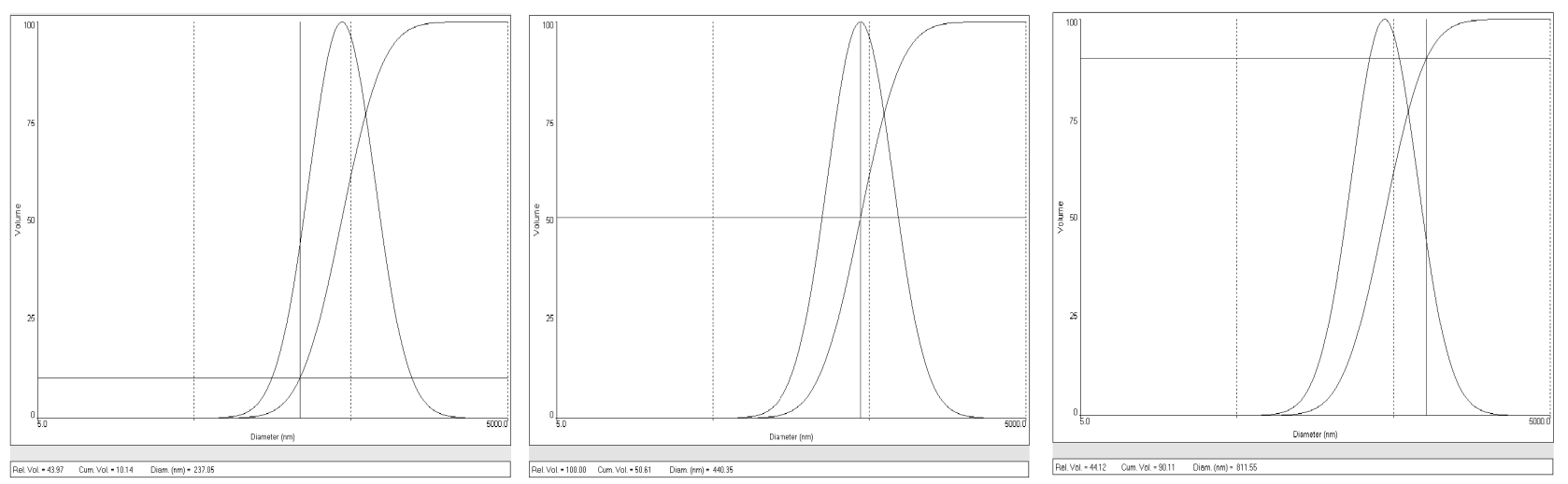

Fig.6 Three $\mathrm{x}$-axis values on volume of laser diffraction of coal bottom ash

Statistical interpretation of particle size distribution is as follows:

a) the value of the D10 parameter is $237.05 \mathrm{~nm}$ which signifies that the volume of the particles with the diameter less than $237.05 \mathrm{~nm}$ represents $10 \%$ of the total volume;

b) the volume of the particles with the diameter less than $440.35 \mathrm{~nm}$ represents $50 \%$ of the total volume (parameter D50 $=440.35 \mathrm{~nm}$ )

c) $\mathrm{D} 90=811.55 \mathrm{~nm}$; the volume of the particles with the diameter less than $811.55 \mathrm{~nm}$ represents $90 \%$ of the total volume.

Surface distribution gives information which is correlated with the reactivity of the particles that form the analyzed coal bottom ash fraction. This is shown in fig. 7.
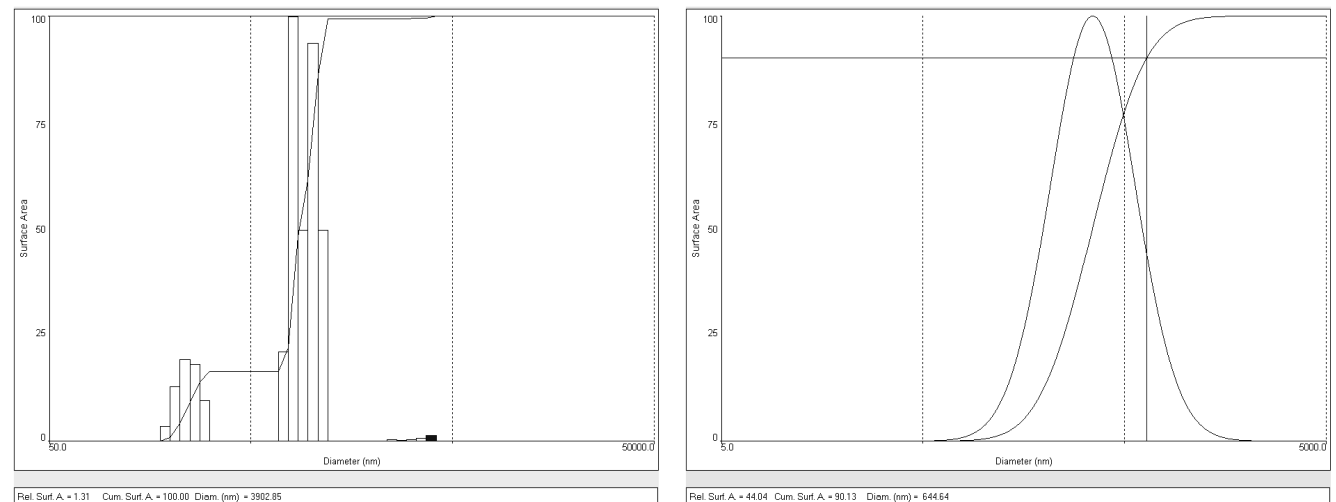

Fig.7 Particle size distribution of coal bottom ash as a surface distribution 
In this case, the values of statistical parameters are:

$\mathrm{D} 10=188.29 \mathrm{~nm}$

$\mathrm{D} 50=342.02 \mathrm{~nm}$

D90 $=644.64 \mathrm{~nm}$; it shows that the surface of the particles with the diameter less than 644.64 $\mathrm{nm}$ represents $90 \%$ of the total surface. This value is inferior to that of the second size distribution class. The major influence on the reactivity of coal bottom ash is the one of the particulate matter that are within the interval [187.4 - 293.9] $\mathrm{nm}$.

The presence in coal bottom ash of particulate matter reprezents a threat for the neighboring area of the coal bottom warehouse due to the wind that blows and makes particle matter travel long distances (the city of Drobeta Turnu - Severin, with a population of approximately 100,000 inhabitants is situated $6 \mathrm{~km}$ away from the coal bottom ash warehouse).

Studying particle size distribution of the coal bottom ash from the large combustion from LCP Halanga results in finding alternatives to use it in producing concrete or for road and rail bases [12]. It is therefore improved the environmental performance of LCP Halanga by diminishing the quantity of waste produced and by a decrease in the level of pollution of the air and of the soil [3].

\section{Conclusions}

Particle size distribution shows that in the composition of the coal bottom ash were found particles with nanometer dimensions. When reducing the size, the surface area increases, which results in an increase of the chemical reactivity of these particles.

In coal ash from LCP Halanga was found particulate matter with the diameter of less than $1 \mathrm{~nm}$. To reduce the concentration of nanoparticles, there must be established correlations between the coal quality, combustion process parameters and equipment characteristics.

Studying the size distribution fractions contributes to the transformation of coal bottom ash in secondary material for producing concrete.

When used adequately, coal bottom ash improves the environmental performance through:

- improving the quality of the environment near the combustion plants based on coal;

- saving natural resources;

- reducing the consume of energy and also the emissions of greeenhouse gases when producing construction materials.

\section{References}

[1] http://www.eia.gov, International Energy Statistics - EIA.

[2] G. Singh, Environmental Aspects of Coal Combustion Residues from Thermal Power Plants, in: Thermal Power Plants - Advanced Applications, M, Rasul (Eds.), ISBN 978-953-51-1095-8, http://www.intechopen.com/books/thermal-power-plants-advanced applications/ environmental-aspects-of-coal-combustion-residues-from-thermal-power-plants,. [3] http://eescopinions.eesc.europa.eu/viewdoc.aspx?doc=ces/ccmi/ccmi087/ro/ces15972011_ac_ro.doc, Processing and exploitation of industrial and mining waste, CCMI/087, Brussels, 2011.

[4] K. Juda-Rezler, D. Kowalczyk, Size distribution and trace elements contents of coal fly ash from pulverized boilers, Polish Journal of Environmental Studies, vol. 22, No. 1, 2013, p. 25-40, ISSN: 1230-1485, Olsztyn, Poland.

[5] BREF Large Combustion Plants, available at http://www.anpm.ro.

[6] U. Kant, V. K. Saxena, A. Sarkar, Atul K. Varma, K. K. Mishra, Characterization of Coal ash from a Captive Power plant for Potential End uses, Proceedings of the Eurocoalash 2012 Conference,Thessaloniki, Greece, September 25-27 2012, http:// www.evipar.org/.

[7] I. Petean, G. Arghir, A. Braşovan, V. Codrea, R. Flavia Câmpean, A. G. Hosu - Prack, minerals distribution in coal fly ash from Paroseni power plant, http://stiintasiinginerie.ro/wpcontent/uploads/2014/01/78-DISTRIBU\%C5\%A2IA-MINERALELOR-\%C3\%8EN-

CENU\%C5\%9EA-DE-HUIL\%C4\%82.pdf. 
[8] Brookhaven, 90 Plus Nanoparticle Size Analyzer, Instruction Manual.

[9] M. S. H. bin Mohd Sani, F. bt Muftah, Z. Muda, The Properties of Special Concrete Using Washed Bottom Ash (WBA) as Partial Sand Replacement, International Journal of Sustainable Construction Engineering \& Technology Vol 1, No 2, December 2010, p. 65- 76.

[10] G. Vasudevan, Performance on coal bottom ash in hot mix asphalt, International Journal of Research in Engineering and Technology, Volume: 02 Issue: 08 | Aug-2013, http://www.ijret.org. [11] ISO 13320-1:2009 Particle size analysis - Laser diffraction methods.

[12] A. Premo Black, New study finds utilizing coal ash in roads and bridges, Ash at Work Issue 1 2011, pg 8-13, http://www.acaa-usa.org/Portals/9/Files/PDFs/Ash_at_Work_final_LR.pdf. 